\title{
Fourth-Line Therapy
}

National Cancer Institute

\section{Source}

National Cancer Institute. Fourth-Line Therapy. NCI Thesaurus. Code C133522.

Treatment that is given when the first three treatments don't work, or stop working. 